DOI: $10.26754 /$ ojs_aem/aem.2019304431

Aragón en la Edad Media

Recibido: $17 / 05 / 2020$

30 (2019) 325-349

Aceptado: 01/06/2020

e-ISSN: 2387-1377

ISSN: 0213-2486

\title{
LA RELACIÓN DE ALFONSO III DE ARAGÓN (1285-1291) CON LA MONARQUÍA INGLESA
}

\author{
THE RELATIONSHIP BETWEEN ALFONSO III OF ARAGÓN (1285-1291) \\ AND THE ENGLISH MONARCHY
}

Francisco Saulo RoDRíGUEZ LAJUSTICIA
Universidad de Cantabria
rodriguezfs@unican.es

Resumen: La relación entre Aragón e In-

Abstract: The relationship between glaterra durante el reinado de Alfonso III Aragon and England during the reign of de Aragón (1285-1291), también conocido por la historiografía como «el Franco»o «el Liberal», fue muy cercana y no solo con Eduardo I, sino también con su esposa la reina Leonor de Castilla. Como fruto de esa alianza se firmaron los tratados de Olorón (1287) y Canfranc (1288) en el seno de unas turbulentas relaciones entre los reinos europeos. Aunque Thomas Rymer transcribió la mayoría de los documentos de esta relación entre los siglos XVII y XVIII, no incluyó todos los diplomas existentes y se equivocó en la datación de algunos de ellos. Este artículo completa el trabajo de Rymer y analiza qué temas se trataron entre los reyes Alfonso III of Aragon (1285-1291), also known by historians as «the Franco» or «the Liberal», was very close and not only with Eduardo I, but also with his wife Eleanor of Castile. As a result of this alliance, the treaties of OloronSainte-Marie (1287) and Canfranc (1288) were signed within a lot of turbulent relations between the European kingdoms. Although Thomas Rymer transcribed the most of the documents about this relationship between the $17^{\text {th }}$ and $18^{\text {th }}$ centuries, he didn't include all the existing documents and he was wrong in the dating of some of them. This work completes Rymer's study and 
de Aragón e Inglaterra durante sus muy habituales contactos.

Palabras clave: Alfonso III de Aragón, Eduardo I de Inglaterra, Leonor de Castilla, relaciones internacionales, siglo XIII. analyzes which topics were discussed between the kings of Aragon and England during their very regular contacts.

Key words: Alfonso III of Aragon, Edward I of England, Eleanor of Castile, international relations, $13^{\text {th }}$ century.

\section{Introducción}

En muchos aspectos, Alfonso III de Aragón (1285-1291) sigue siendo todavía un gran desconocido al no haber sido objeto hasta el momento de ningún estudio específico dirigido a su persona, a excepción, si cabe, de una obra que escribió Ludwig Klüpfel a comienzos del siglo XX de difícil acceso además de comprensión para cualquiera que no entienda el alemán (Klüpfel, 1911). ${ }^{1}$

Situado cronológicamente entre monarcas de renombre como Jaime I, Pedro III y Jaime II que sí han llamado la atención de los historiadores, Alfonso III ha pasado en gran medida bastante desapercibido y aquellos que le han dedicado algunas líneas, por lo general tampoco muchas, lo han hecho en estudios que versan sobre temáticas mucho más amplias. A día de hoy, si los reyes anteriormente citados cuentan con biografías y densos estudios elaborados en el siglo XXI, en el caso de Alfonso III los estudios más completos siguen siendo los que Ferrán Soldevila escribió en la década de los sesenta de la pasada centuria (Soldevila, 1963). ${ }^{2}$

Al mismo tiempo que el panorama historiográfico sobre Alfonso III es un tanto desolador, paradójicamente las circunstancias internacionales en las que se vio inmerso su reinado no faltan en ningún manual sobre Historia Medieval en tanto en cuanto hablamos de un momento crucial en el juego de relaciones

1 Con todo, el amplio comentario que del trabajo de Klüpfel realizó José Jordán de Urríes, con traducción de extensos fragmentos del original, permite acceder, comprender y valorar en su justa medida la aportación de este investigador alemán que falleció en un accidente en la comarca del Ampurdán (Jordán de Urríes, 1914).

2 Centrando nuestra mirada en estudios más específicos, encontramos datos de interés sobre el reinado de Alfonso III en trabajos como los que Cosme Parpal dedicó a la conquista de Menorca de 1287 (Parpal, 1964) o Luis González a la Unión aragonesa (González, 1975). Con todo, y aunque son aportes de indudable interés y calidad, sigue faltando uno que trate con profundidad el reinado de este monarca. 
entre las distintas potencias que pretendían el control del Mediterráneo. Así, por ejemplo, citando uno de los más recientes:

Pedro III vio ampliado su reino, con la incorporación de Sicilia a su Corona, que cedió a su segundo hijo, el futuro Jaime II de Aragón, al tiempo que dejaba el trono aragonés a su primogénito, Alfonso III. El nuevo rey de Nápoles, Carlos II de Anjou, renunció a la corona siciliana (Tratado de Barcelona, de 1287) a cambio de su liberación, pero dicho Tratado no fue aceptado por el Papa, por lo que el napolitano tuvo que volver a ratificar su renuncia mediante el Tratado de Olorón (1288), esta vez con la mediación de Eduardo I de Inglaterra. Tampoco fue aceptado por el Papa, aún cuando, en esta ocasión, se había producido la liberación de Carlos II. Por el Tratado de Tarascón (1291), se pretendió poner fin, definitivamente, al problema siciliano (Donado, Echevarría y Barquero, 2014: 60).

En lo que se refiere a la monarquía inglesa dejaré intencionadamente para más adelante las principales referencias de obligada consulta para el tema que abordo en este artículo, puesto que, a diferencia de Alfonso III, tanto Eduardo I - responsable de, entre otras cosas, la expulsión de los judíos de Inglaterra en 1290 o de importantes campañas de expansión contra Gales y Escociacomo su primera esposa, Leonor de Castilla, han generado una abundantísima cantidad de publicaciones sobre ellos de muy diferente signo, a las que hay que sumar el interés que los reyes generaron tanto para novelistas como para guionistas cinematográficos. ${ }^{3}$

Para todo lo que se refiere a las relaciones entre Inglaterra y las demás potencias extranjeras, la obra de referencia que más ha sido citada por parte de historiadores de todas las generaciones ha sido la que compiló Thomas Rymer a caballo entre los siglos XVII y XVIII, conocida por lo general por su forma abreviada como los Foedera y que consiste en, como lo definió Gerard Reedy, «thousands of parallel columns of objective, passionless, magnificent documentation about English history from 1101 and the reign of Henry I» (Reedy, 1978: 412).

Desde ese punto de vista, la inmensa mayoría de la correspondencia que tuvo lugar entre la monarquía inglesa y Alfonso III de Aragón en el marco de

3 Aunque no se trate de referencias válidas en un trabajo académico, creo que no debe dejar de citarse en el terreno de la novela la que Jean Plaidy, seudónimo de la escritora Eleanor Burford y prolífica autora de una larga serie de novelas dedicadas a la monarquía inglesa que va desde el siglo XI hasta el XIX, dedicó en 1979 a Eduardo I bajo el significativo título original de Hammer of the Scots (Plaidy, 1996). En lo que se refiere al cine y aunque sea una película plagada de inexactitudes, resulta inexcusable recordar Braveheart (Mel Gibson, 1995), muestras estas más que evidentes del especial interés que Eduardo I ha despertado en el mundo anglosajón y que va más allá de muchos de sus contemporáneos. 
la estrecha colaboración que hubo entre ellos en todo momento fue ya transcrita y publicada por Rymer en sus Foedera, si bien, al haber trabajado exclusivamente con la documentación contenida en los archivos ingleses y no haber explorado los que se custodian en otros lugares como el Archivo de la Corona de Aragón, hay algunos diplomas que no figuran en su magno trabajo, además de algún que otro error menor de datación.

Por este motivo, el trabajo que presento a continuación en este reconocimiento académico al profesor Juan Utrilla intentará cubrir las lagunas que dejó Rymer, además de profundizar en otras cuestiones no tratadas por él.

\section{La relación de Alfonso III con Eduardo I}

Si los tratados internacionales que se suscribieron en este periodo han encontrado su reflejo en los principales manuales de Historia Medieval, lo mismo sucede, como no podía ser de otra manera, con todos aquellos estudios en los que se aborda la historia de Aragón y, más en concreto, la de la Edad Media. Una sucinta aproximación a lo que acontece en estos momentos podemos encontrarla, por ejemplo, en Canellas (1986) o en Rábade, Ramírez y Utrilla (2005).

Los contactos de Alfonso III con la monarquía inglesa pueden rastrearse a la época en la que él era infante, tal y como ha demostrado Stefano Cingolani, con un documento de 2 de mayo de 1282 en el que le informa de su buena salud o con otro del 12 de octubre redactado con el mismo propósito (Cingolani, 2015: 445-446 y 488). ${ }^{4}$ El momento no podía ser más oportuno: Pedro III se encontraba enfrentado de lleno a los Anjou por el dominio de Sicilia y el infante Alfonso, ante el incierto devenir que podían tener los acontecimientos intentaba que no languidecieran las buenas relaciones con la monarquía inglesa que siempre había tenido su padre.

Ciertamente, en tanto en cuanto la política que desarrolló Alfonso III se caracterizó fundamentalmente por la continuidad con respecto a la de su padre, no se puede entender la relación de este con Inglaterra sin echar un vistazo al periodo de Pedro III y ver cómo, en 1273, recién proclamado Eduardo I 
como monarca inglés y siendo todavía Jaime I rey de Aragón, ya se proyectó la boda entre el niño Alfonso y la todavía más niña Leonor (Darwin Swift, 1890: 326-328).

El enfrentamiento que Pedro III mantuvo con los Anjou, la incorporación de Sicilia a los dominios aragoneses y la consiguiente excomunión que esto supuso para la monarquía aragonesa, provocó que Eduardo I lo dilatara cada vez más - aunque lo habitual era que, tan pronto se concertaba un matrimonio, las princesas fueran llevadas lo antes posible a las tierras del que sería su marido a fin de familiarizarse tempranamente con las peculiaridades de su futuro reino (Cingolani, 2015: 61) — , amparándose en la guerra que el rey inglés mantenía contra Gales cuando, en realidad, quería evitar a toda costa un enfrentamiento con la Santa Sede (Goodman, 1989: 83). ${ }^{5}$

La muerte de Pedro III en 1285, así como la de Carlos I de Anjou, Felipe III de Francia y del papa Martín IV también en ese mismo año, provocó que en todos los territorios fueran sus respectivos herederos los que continuaran la política de sus antecesores. Eduardo I quedó como el único que había asistido a todas estas fricciones internacionales desde el principio y que, al no fallecer hasta 1307, las vería concluir o, cuando menos, atenuarse a partir del tratado de Anagni de 1295 y de la indiscutible supremacía de Felipe IV de Francia tras la muerte de Bonifacio VIII.

Considerado por tanto Eduardo I como el árbitro por excelencia para dirimir todas estas cuestiones, en la segunda mitad de la década de los ochenta se dio la necesidad perentoria de normalizar las relaciones entre Aragón y Francia o, cuando menos, de evitar nuevos enfrentamientos armados. Con este fin, Alfonso III facultó a partir de mayo de 1286 al monarca inglés para que llevara las riendas de las negociaciones conducentes a la formalización de una tregua (docs. 1 y 2), aun cuando al principio se manifestaron algunas dificultades (docs. 3 y 4), especialmente por parte de un Honorio IV que, también en ese mismo mes de mayo, calificaba a los aragoneses de indevotos (Rymer, 1789: 8$){ }^{6}$

5 Con todo y pese a ello, sí se celebraron las bodas por verba de presenti con la presencia de emisarios enviados por el rey de Inglaterra para comprobar la entidad de la dote y, además, según el testimonio de la redacción definitiva de las Gesta comitum a las vistas de Olorón entre ambos reyes, también estuvieron presentes la reina Leonor de Castilla y su hija (Cingolani, 2012: 238-240).

6 Los documentos que figuran en el apéndice, bien transcritos o bien únicamente con su regesta si ya los editó Thomas Rymer, aparecen por orden cronológico. En dicho apéndice figura si los editó Rymer o no, junto a la página en el caso en que así sea. Cuando me refiero a documentos que editó Rymer pero 
En todo este contexto de comunicaciones entre monarcas cobran especial importancia las cartas de creencia, documentos sin valor legal per se - a diferencia de los acuerdos o los tratados de paz- en los que el rey identificaba a las personas que le representaban e, indicándole que acudían ante él como enviados suyos, rogaba al destinatario que creyera todo lo que le contarían (Chaplais, 2003: 82). En este sentido, en tanto en cuanto los temas a debatir se trataban muchas veces verbalmente mediante estos mensajeros, nos encontramos con la circunstancia de que la que ya habló Stefano Cingolani: tenemos constancia de comunicación entre dos monarcas, pero no sabemos a ciencia cierta el asunto tratado al no aparecer reflejado por escrito (Cingolani, 2015: 60).

En el verano de 1287, después de un primer semestre en el que Alfonso III se encargó de recaudar fondos para realizar el viaje y celebrar su encuentro con Eduardo I, se firmó el tratado de Olorón en el que:

El aragonés demandaba el reconocimiento internacional de las recientes incorporaciones de la Corona, es decir, de los reinos de Mallorca, Menorca y Sicilia; quería también la supresión de los derechos de Carlos de Valois, y la creación del reino de Murcia, que sería entregado al infante castellano Alfonso de la Cerda; ofrecía, a cambio, liberar a su rehén Carlos de Salerno, tras el pago de un cuantioso rescate (Rábade, Ramírez y Utrilla, 2005: 425).

Sin ninguna duda, el tema que más preocupaba internacionalmente era el hecho de que Carlos II de Anjou, príncipe de Salerno, hubiera sido hecho prisionero por Aragón y que fuera utilizado como un continuo instrumento de Alfonso III para conseguir lo que quería, por lo que su liberación empezó a ser considerada prioritaria como paso previo para abordar cualquier tema. En este sentido, Eduardo I era consciente de que, en sus encuentros con los aragoneses, debía conseguir a toda costa la liberación del príncipe de Salerno; esta liberación se había convertido también en el objetivo personal de un rey inglés incómodo entre la espada y la pared, esto es, entre Aragón y la Santa Sede, y ante su constante temor de desagradar al papa con algún posible error. En definitiva, como ha señalado Caroline Burt, la liberación del príncipe de Salerno se convirtió, casi como si se tratara de una cruzada, en el objetivo número uno

que no figuran en el apéndice por no contener una comunicación directa entre ambos monarcas, aludo a la referencia bibliográfica. Por último, cuando hablo de documentos que no figuran en el apéndice y que no están tampoco en la obra de Rymer, incluyo la referencia archivística. 
para un rey inglés que deseaba ser percibido como defensor de los intereses de la Iglesia (Burt, 2013: 149).

Más allá de la liberación del príncipe de Salerno, lo que no se produjo tras Olorón, el encuentro entre Alfonso III y Eduardo I sirvió también para tratar otros temas tales como la reafirmación del acuerdo matrimonial entre el rey aragonés y la princesa Leonor de Inglaterra; como ya he comentado, la excomunión que había decretado Martín IV contra Pedro III a raíz de la toma de Sicilia había enfriado bastante dicho acuerdo. El documento, dotado de la mayor solemnidad, es en sentido estricto la promesa de Eduardo I de que entregaría a su hija a Alfonso III y contiene los juramentos de diversos miembros del alto clero y la alta nobleza, tanto inglesa como aragonesa (doc. 8). ${ }^{7}$

Por lo demás, este tipo de encuentros solían generar problemas de convivencia que después requerían ciertas reparaciones. Si el hecho de que un león que llevaba Eduardo I se escapara y matara a un caballo (Prestwich, 2008: 324) puede ser considerado como una mera anécdota, las fricciones entre ingleses y aragoneses producidas en Olorón y la denuncia por parte de Eduardo I de lo que él consideraba agravios cometidos contra sus súbditos provocaron que Alfonso III encargase al sobrejuntero de Jaca dos misiones: que designara a cuatro hombres para desplazarse a Canfranc a fin de llegar a un acuerdo; ${ }^{8} \mathrm{y}$ que, a la par, ordenara que ninguno de sus súbditos impidiera tanto a los ingleses como a Gastón de Bearne — quien también decía haber sido atacado- su respectivo desplazamiento para tratar sobre esto. ${ }^{9}$

El tratado de Olorón, considerado por Michael Prestwich como un exclusivo triunfo aragonés (Prestwich, 2008: 325), no trajo consigo la liberación del príncipe de Salerno, por lo que fue automáticamente rechazado tanto por Felipe IV de Francia como por el nuevo papa Nicolás IV (Rábade, Ramírez y Utrilla, 2005: 425). El nuevo pontífice mostró desde el primer momento que estaba plenamente dispuesto a seguir la política de sus antecesores. Para ello, en marzo de 1288 encargó, una vez más, a Eduardo I que procurara por todos los medios posibles la liberación del príncipe de Salerno (Rymer, 1789: 22-23).

7 Puesto que, al haberlo transcrito Rymer, el documento no figura en el apéndice, señalaré que se citan, entre otros, los obispos de Durham, Norwich y Valencia, los condes de Pembroke y Lincoln, así como todos los que habitualmente actuaban como mensajeros entre ambas cortes.

8 Archivo de la Corona de Aragón (ACA), Real Cancillería, reg. 70, f. 159v.

9 ACA, Real Cancillería, reg. 70, f. 160. 
Miguel Marzal abordó de forma muy certera lo compleja que resultaba la liberación del príncipe de Salerno. Por un lado, Alfonso III veía cómo todos a su alrededor le presionaban para ello y además a partir de julio de 1288 el tratado de Lyon estrechaba las relaciones entre Francia y un Sancho IV de Castilla a quien Aragón no reconocía como el monarca legítimo. Y por el otro lado, su hermano Jaime, rey de Sicilia en aquellos años junto a la madre de ambos, la reina Constanza, estaba radicalmente en contra de la liberación del príncipe al ser plenamente consciente de que, si esta se producía, era cuestión de tiempo que reclamara la isla (Marzal, 1997: 436-437).

Aunque Eduardo I tenía el encargo de la Santa Sede de presionar a Alfonso III ya desde la primavera de 1288 - si acaso alguna vez dejó de tenerlo tras su fracaso en Olorón-, lo cierto es que hasta finales de octubre no se celebró el nuevo encuentro, en parte porque el rey aragonés estuvo convaleciente de una enfermedad de la que él mismo hacía mención y que fue retrasando las vistas $\mathrm{y}$, en parte también, porque se vio en la constante necesidad de convencer a su hermano Jaime de que no tenía otro remedio más que liberar al príncipe de Salerno, lo que puede verse en la larga exposición del tema que le hizo a comienzos de junio (La Mantia, 1908: 355)..$^{10}$

Recuperado Alfonso III de su enfermedad, concedidos los preceptivos guiajes para que el desplazamiento de la comitiva inglesa hasta Canfranc fuera lo más segura posible (doc. 16) y considerando también que, según los nuncios aragoneses, Felipe IV ya había intentado boicotear en verano las conversaciones entre Aragón e Inglaterra ${ }^{11}$, finalmente se produjo el encuentro y el príncipe de Salerno fue liberado por parte de los aragoneses:

A cambio de la entrega de sus dos hijos en rehenes e importantes indemnizaciones de dinero sobre hipotecas en posesiones que Gastón de Bearn tenía en Cataluña. Carlos de Anjou se compromete a poner en vigor las treguas entre Aragón y Sicilia pactadas en Olorón y conseguir del papa la revocación de la investidura del reino de Aragón hecha por Martín IV a Carlos de Valois. Alfonso III devolverá el dinero pactado en cuanto se cumpla este tratado y Carlos de Anjou promete reintegrarse a su prisión caso de incumplimiento del tratado (Canellas, 1986: 23).

10 ACA, Real Cancillería, reg. 77, ff. 2-3. La Mantia realizó una transcripción parcial y no incluyó todos los añadidos que figuran más allá de la cláusula de la data en los que Alfonso III va relatando cómo fueron desarrollándose las conversaciones entre los reyes de Aragón e Inglaterra y qué argumentos expuso cada parte.

11 ACA, Real Cancillería, reg. 77, f. 4. 
Podría decirse que, con el tratado de Canfranc, la gran misión diplomática de Eduardo I había concluido y este había podido resarcirse finalmente del fracaso sufrido en Olorón en lo referente a la liberación del príncipe. Con ello logró el visto bueno a su actuación por parte del papado y consiguió así, de entrada, el allanamiento hacia la normalización de relaciones entre Aragón y la Santa Sede, lo que también interesaba a Inglaterra considerando una vez más el pacto matrimonial suscrito el año anterior.

La implicación máxima de Eduardo I en todo este asunto queda puesta de manifiesto si se tiene en cuenta cómo, a fin de facilitar que el asunto llegara a buen puerto, no se echó atrás a la hora de realizar importantes sacrificios que incluso comprometían a sus súbditos. Así, hizo con la entrega de treinta mil marcos y un cuantioso número de rehenes ingleses a modo de garantía desinteresada hasta que Carlos de Anjou empezase a cumplir las condiciones de lo pactado y hasta que dichos rehenes fueran sustituidos por otros tantos provenzales (Jordán de Urríes, 1914: 447).

Si bien en los dos meses siguientes Alfonso III fue obteniendo de las principales ciudades aragonesas el compromiso de que respetarían los acuerdos de Canfranc y se reafirmaba en la inmediata liberación de los rehenes ingleses tan pronto llegaran los provenzales (Rymer, 1789: 31-41), desde todos los puntos de vista, el tratado de Canfranc fue un absoluto fracaso. Por un lado, Nicolás IV no tardó en eximir a Carlos de Anjou de todas las condiciones que se le habían impuesto para su liberación (Marzal, 1997: 439); Aragón enseguida comenzó a recelar de la actitud del príncipe de Salerno y, en opinión de Michael Prestwich, Eduardo I también empezó a considerar que toda la labor realizada para conseguir su liberación había sido hecha en vano (Prestwich, 2008: 326).

Al tratado de Canfranc le siguieron una serie de graves problemas internos para Alfonso III por parte de unos unionistas que, ya desde su misma subida al trono, se habían caracterizado por aliarse con todos sus enemigos, intentando alcanzar su propia tregua con Felipe IV y reconciliarse con el papado al margen de lo que hiciera el rey aragonés (Sarasa, 1984: 36). Manuel Sánchez ha sintetizado con gran acierto todo lo que sucedió entre finales de 1288 y la primera mitad de 1289:

La coyuntura era ciertamente muy grave: mientras el pacto de Canfranc (octubre de 1288) provocaba una nueva agitación unionista, dos meses después, Alfonso el Liberal declaraba la guerra a Sancho IV de Castilla; por 
otro lado, en junio de 1289, los franceses tomaron Salvatierra, en la frontera navarra y, en agosto del mismo año, el monarca catalanoaragonés hubo de acudir a la Cerdaña para contrarrestar la invasión coordinada de Francia y de Jaime II de Mallorca (Sánchez, 1998: 68).

En el primer semestre de 1289 no se observa, en líneas generales, una actitud ni especialmente agresiva ni quejumbrosa de Aragón con respecto a la Santa Sede. Alfonso III se mostró especialmente interesado en reunirse con el papa - probablemente para indagar cuál era la nueva situación después de que Aragón hubiera liberado al príncipe de Salerno, especialmente en lo referente a la excomunión de su figura-, disculpándose de antemano a comienzos de enero por no haber podido acudir a causa de su enfermedad al encuentro que se había concertado con anterioridad. ${ }^{12}$

Puede aventurarse que en los primeros meses de 1289 sí que había un cumplimiento de las condiciones pactadas en Canfranc en lo que se refiere a las cuestiones menores, esto es, al intercambio de rehenes. De este modo, el 9 de marzo Alfonso III confirmó al rey de Inglaterra que Aragón había recibido los veinte rehenes marselleses que se habían estipulado a finales de octubre para liberar al príncipe de Salerno (doc. 22), así como los ingleses que Eduardo I le había enviado como garantía de la entrega de los provenzales (doc. 23).

Esta presunta tranquilidad de Alfonso III con respecto a las consecuencias del tratado de Canfranc no era en realidad más que producto de la máxima concentración que le exigían otros asuntos para él más preocupantes, en la línea de lo que manifestaba Manuel Sánchez. Con todo, en lo que se refiere a asuntos internacionales, Eduardo I seguía siendo el intermediario por excelencia del monarca aragonés, como se ve en el hecho de que en mayo le autorizase para negociar por parte de Aragón una prórroga de las treguas con Francia (doc. 24).

Sin embargo, en el segundo semestre, Alfonso III empezó a ser cada vez más consciente de que la liberación del príncipe de Salerno había sido en vano y que este, más allá de la cesión de rehenes, no iba a cumplir las condiciones que se habían establecido en Canfranc y, en especial, el hecho de que su puesta en libertad estaba completamente condicionada a que respetara a Jaime en el trono siciliano, so pena de volver a prisión si no estaba dispuesto a ello (Tout, 1905: 171). 
Si en el mes de septiembre Alfonso III se dirigió directamente a Carlos II de Anjou para acusarle de no cumplir lo que se había pactado (Rymer, 1789: 50), desde noviembre de 1289 la presión recayó en la monarquía inglesa. El rey aragonés volvió a recurrir a Eduardo I para pedirle una vez más, esta vez de forma un tanto agria, que hiciera de intermediario y se implicara en un problema en el que Aragón entendía que no se había cumplido nada de lo hablado en Canfranc, ni por parte del príncipe de Salerno ni por parte de una Santa Sede que seguía manteniendo la excomunión pese a lo que él entendía que había sido un gesto de buena voluntad aragonesa. Una buena prueba del enfado de Alfonso III en esta cuestión la demuestra el hecho de que no sólo escribió a Eduardo I (docs. 25 y 27), sino que también lo hizo a la reina Leonor para que presionara a su marido a ejercer lo que se le pedía en este asunto (doc. 26).

Eduardo I recogió una vez más el testigo que se le ofrecía y la documentación demuestra cómo desde enero de 1290 de nuevo trabajó en concertar nuevas treguas entre Aragón y Francia (docs. 28 y 29), si bien en esta ocasión la coyuntura internacional que condujo al tratado de Tarascón (1291) — por el cual «Roma levanta la excomunión, rehabilitando al rey en Aragón-CataluñaValencia-Mallorca, a cambio del pago de censos adeudados y de no apoyar a Jaime de Sicilia en las actuaciones que la Santa Sede mantuviera sobre la isla» (Rivero, 1982: 188) - , fue relevando progresivamente al monarca inglés como principal elemento negociador. En 1290 y 1291 los contactos entre ambos reyes fueron mucho menores, encargándose ya incluso de ellos el infante Pedro, el hermano menor de Alfonso y Jaime (Rymer, 1789: 61).

No significa esto ni mucho menos que ya no se produjeran más contactos entre Aragón e Inglaterra. Un acuerdo establecido entre Aragón y Sicilia en enero de 1291 como paso previo al tratado de Tarascón contó con la presencia de varios nuncios enviados por el monarca inglés (Rymer, 1789: 77-78). Y en mayo de ese mismo año todavía un Alfonso III ya cercano a la muerte enviaba una carta de creencia a Eduardo I a favor de varios emisarios suyos. No obstante, todos estos contactos ya no tuvieron la misma frecuencia ni intensidad de la que hubo en los momentos en que se suscribieron los tratados de Olorón y de Canfranc.

\section{La relación de Alfonso III con la reina Leonor de Castilla}

Aunque los tratados anteriormente mencionados resultan lo más visible de la relación entre Aragón e Inglaterra durante el reinado de Alfonso III, lo cier- 
to es que hay muchos otros aspectos que también la demuestran, aunque puedan ser considerados en el terreno de lo anecdótico. Así sucede, por ejemplo, con el dato que destaca Rose Walker de los jardineros aragoneses que trabajaban en esta época al servicio de la reina Leonor (Walker, 2007: 68).

No creo que sea necesario indicar aquí el especial repunte que han experimentado en los últimos años los estudios sobre reginalidad y sobre la destacadísima labor que las reinas ejercieron en las tareas de gobierno durante el periodo medieval, muchas veces en consonancia con sus maridos, pero en otras al margen o incluso a pesar de estos. El papel de Leonor de Castilla como reina consorte de Eduardo I y las buenas relaciones que ambos mantuvieron siempre es una coincidencia prácticamente plena por parte de la historiografía.

Durante la práctica totalidad del reinado de Alfonso III había tres reinas con el mismo nombre en la corte inglesa: Leonor de Provenza, Leonor de Castilla y Leonor de Inglaterra, que eran respectivamente la madre, esposa e hija mayor de Eduardo I. Salvo con esta última que hubiera sido su esposa de no haber fallecido, Alfonso III mantuvo relaciones epistolares con las otras dos, lo que obliga al historiador a estar especialmente atento para saber a quién se estaba dirigiendo.

De entre ellas tres, el mayor peso político parece haberlo ejercido Leonor de Castilla, algo comprensible teniendo en cuenta que ella era la esposa del rey. Su influencia o, cuando menos, su presencia es algo que parece más que evidente en la inmensa mayoría de las acciones emprendidas por Eduardo I en los años setenta y ochenta — la reina falleció en noviembre de 1290 - y, en lo que atañe a la relación entre Inglaterra y Aragón, Sara Cockerill ha destacado la influencia que ejerció para que saliera adelante el matrimonio de su hija mayor con el rey aragonés (Cockerill, 2014). ${ }^{13}$

Exceptuando el citado documento de octubre de 1282 publicado por Stefano Cingolani y dirigido a toda la familia real inglesa, las comunicaciones de Alfonso III con las mujeres de dicha familia se concentran entre 1287 y 1291 ; en ocasiones se trata de asuntos relacionados con la intermediación, pero no exclusivamente.

Al igual que sucedía con las comunicaciones entre Alfonso III y Eduardo I, no siempre conocemos el contenido exacto de la correspondencia entre el rey de Aragón y la reina de Inglaterra y muchas veces ni siquiera se nos ha con- 
servado físicamente el documento en sí, si bien podemos saber que existió un contacto entre ellos gracias a que así se hace constar en otro diploma. Este sería el caso, por ejemplo, de una absolución que el rey aragonés concedió en agosto de 1287 a Oger de Canfranc a petición de la reina Leonor («ad preces illustrissime domine regine Anglie», doc. 12) después de que el sobrejuntero de Jaca le hubiera acusado de cometer un crimen.

Asuntos políticamente más delicados son los que se trataron en junio de 1288, apenas un mes antes de que Francia y Castilla firmaran el tratado de Lyon en contra de Aragón. En el centro del conflicto se encontraba el hecho de que Alfonso III no reconociera a Sancho IV como rey de Castilla y sí que en cambio lo hiciera con los infantes Alfonso y Fernando de la Cerda, retenidos en territorio aragonés después de que en 1277 hubieran huido de Castilla «para refugiarse en la corte francesa, ya que su vida corría peligro a causa de la ambición de su tío, el infante Sancho, que quería que fuese reconocido el propio derecho a la sucesión de su padre, el rey Alfonso el Sabio, contra quien se levantó en armas» (Ferrer, 2005: 19).

Sin ánimo de profundizar en detalles que nos apartarían del propósito de este trabajo, Àngels Masià ha destacado cómo dicho apoyo aragonés a los infantes de la Cerda

[...] no era un castigo a lo que juzgaban una traición, ni un interés hacia un cambio de rama dinástica en Castilla, sino la intención de adquirir unas posesiones que ensanchasen sus dominios, a base de anular las consecuencias de los tratados anteriores, que limitaban la expansión aragonesa hacia el sur. Por lo tanto, la ayuda prestada a la causa de de la Cerda era interesada y, en consecuencia, dicho apoyo tenía un precio. Éste fue la cesión del reino de Murcia (1289) (Masià, 1992: 258).

En este contexto, no se escatimó ningún esfuerzo en las labores diplomáticas de unos y de otros y las mujeres adquirieron una importancia de primera mano. Por un lado, la madre de los infantes, Blanca de Francia, era tía de Felipe IV, por lo que Alfonso III consideró que podía jugar un importante papel en el establecimiento de treguas entre Aragón y Francia - o, lo que es lo mismo, intentando impedir la firma del tratado de Lyon y el consiguiente alineamiento francés con Castilla_-, lo que le llevó a indicarle a Eduardo I que, si lo conseguía, automáticamente liberaría a los infantes de la Cerda (doc. 13).

Para intentar frustrar los intereses franco-castellanos, Alfonso III explotó al máximo sus buenas relaciones con la monarquía inglesa y, siendo conscien- 
te de que la reina Leonor también tenía relaciones familiares con la Corona de Castilla, ${ }^{14}$ le escribió para pedirle que hiciera caso omiso de cuanto pudiera haberle contado Sancho IV al respecto, siendo especialmente interesante el detalle de que en esa comunicación parece haberse dirigido también a la reina madre (doc. 15). ${ }^{15}$

Este ejemplo demuestra con creces cómo las mujeres de la realeza no siempre actuaban como meras intermediarias entre varones simplemente para influir en sus hermanos o esposos. Aunque en ocasiones se les pedía que lo hicieran (doc. 26), en muchas otras eran ellas las que llevaban las riendas de determinados asuntos políticos y eran preferidas a los varones o, cuando menos, se les solicitaba audiencia y que estuvieran presentes en el proceso de una negociación o de la simple comunicación de noticias (doc. 21).

\section{Conclusiones}

Quizá la conclusión más evidente que podría desprenderse de este trabajo es que, durante el reinado de Alfonso III, Aragón no permaneció ni mucho menos a la sombra en el contexto internacional, sino que, por un cúmulo de circunstancias que arrancan durante el reinado de su padre, fue relativamente frecuente que se hablara de él por parte de las principales potencias europeas del momento.

En lo que se refiere a la política aragonesa de amistad con Inglaterra, posiblemente el reinado de Alfonso III sea en el que más estrecha fue la colaboración entre ambos reinos, puesto que desde la segunda mitad del siglo XII y hasta este momento el sur de Francia era lo que más había interesado a la monarquía aragonesa. Y, en muchos momentos que vendrían después, también serían más frecuentes las relaciones de Aragón con su vecino reino septentrional que con las islas británicas.

Con todo, y pese a la trascendencia que a medio y largo plazo tuvieron los acontecimientos que se pusieron encima de la mesa entre 1285 y 1291, Alfon-

14 Al ser hermanastra de Alfonso X, era por lo tanto tía de Sancho IV y tía abuela de los infantes de la Cerda.

15 La tinta del documento se encuentra bastante desvaída y las dificultades de lectura son notables, si bien en la dirección, después de haber hecho constar íntegramente los títulos de la reina Leonor, se incluye un «sive matri» que pudiera tratarse de una alusión a Leonor de Provenza, a quien ya se había dirigido en el documento de 1282 que publica Cingolani y en el de 1291 que incluyo en el apéndice (doc. 30). 
so III sigue siendo un rey todavía completamente a la sombra de sus contemporáneos, quizá por haber sido considerado por muchos durante bastante tiempo como un mero continuador de la política de su padre sin tener la brillantez de este y sin suponer lo que supusieron Jaime I o Jaime II en la historia de la Corona de Aragón.

Aunque este artículo no sea sino una aportación suelta a uno de los aspectos de su reinado que ha buscado profundizar un poco más en un tema, la relación entre Alfonso III y Eduardo I, que ya era conocido pero, en mi opinión, desde una perspectiva un tanto superficial, lo cierto es que queda todavía bastante por escribir sobre un monarca del que desconocemos todavía bastantes aspectos que solo podrán cubrirse cuando se aborden sus documentos de forma un tanto más concienzuda de lo que se ha hecho hasta la fecha.

\section{Apéndice documental}

\section{1286, mayo, 13. Huesca.}

Alfonso III comunica a Eduardo I que acepta establecer una tregua con Francia y le indica que ha nombrado para ello a Pedro Martínez de Artasona y a Juan Zapata. - Pub. Rymer, 1789: 8.

2. $[1286, \text { mayo, 13. Huesca }]^{16}$

Alfonso III comunica a Eduardo I que ha recibido a sus mensajeros y le indica que le envía de su parte a Pedro Martínez de Artasona y Juan Zapata con la misma función.

- Archivo de la Corona de Aragón, Real Cancillería, reg. 64, f. 180v.

Excellentisimo et magnifico principi tanquam patri karisimo domino Odoardo, Dei gratia illustri regi Anglie, domino Hiber/nie et duci Aquitanie, Alfonsus, etcetera, salutem et intuitum dilectionis, constanciam ac prosperitatis augmentum.

Excellen/cie vestre notum facimus per presentes nos vidisse venerabiles et discretos viros dompnum Antonium, episcopum / Dunelinensem, et dompnum Iohannem de Veçino, militem, quos ad nos misistis cum literis vestris credulitatis, / et ea que dicti nuncii vestri nobis, pro parte vestra exposuerunt intelleximus et perpendimus diligenter. Quibus ple/narie intelletis deliberavimus ad vestram presenciam mitere

16 En el caso de los documentos a los que les faltan detalles en la cláusula de la data o en los que, como sucede en este caso, se indica que esta es la misma que en el caso anterior («ut supra»; literalmente, como arriba) esta se ha obtenido consultando los diplomas copiados anteriormente en el registro e incluyendo entre corchetes el resultado de dicha consulta a fin de diferenciar estas datas de las que sí constan explícitamente. 
nostros nuncios speciales, scilicet, venerabiles et discre/tos viros, consiliarios et familiares nostros, Petrum Martini de Arthesona et Iohanem Çabata, latores presen/ tium, per quos de responssione et intencione nostra et proposito necnon et de salute ac prosperitate nostra poter[atis] / plenarie informari. Rogantes vos quatenus in hiis et aliis que vobis ex parte nostra retulente fidem / plurimam (tachado: ah d) adhibere velitis et per eos velitis nos de salute, statu et felicibus successi/bus vestris, si placet, reddere certiores. Scientes quod eisdem iniuncximus quod super negociis nostris / vobis tractare habent procedant de vestro consilio et assensu.

Data ut supra.

3. 1286, julio, 25. París.

Eduardo I indica a Alfonso III que ha escuchado a los mensajeros que le había enviado el rey de Aragón, pero que no habían llegado a un entendimiento ante la complejidad de los asuntos que se trataban, motivo por el cual habían quedado retenidos hasta que esto se produjera o hasta que ambos monarcas se encontraran.

- Pub. Rymer, 1789: 12.

4. 1286, julio, 25. París.

Eduardo I indica a Alfonso III que ha establecido las condiciones de una tregua entre Aragón y Francia y que se las ha enviado al papa para que este les de su visto bueno en un plazo de dos meses, rogándole mientras tanto que no ataque a ninguna posesión ni vasallo del rey francés.

- Pub. Rymer, 1789: 13.

\section{5. [1287], febrero, 28. Barcelona.}

Alfonso III comunica a Eduardo I que dos arzobispos enviados por Roma habían llegado a Toulouse para llegar a un pacto con Aragón y que estos mismos legados se dirigían a Burdeos para citarse con él. Igualmente, le dice que no ha podido encontrarse con Pedro Martínez de Artasona pese a que este había sido enviado con urgencia por el monarca inglés para que le transmitiera un mensaje.

- ACA, Real Cancillería, reg. 64, f. 193r.

Excellentisimo et magnifico principi domino Odoardo, Dei gratia illustri regi Anglie, domino Ibernie ac duci Aquitanie, Alfonsus, per eandem, etcetera, / salutem, etcetera.

Vestre regie celsitudini notum facimus quod, nobis existentibus in insula Minorice quam, divino auxilio suffragante, dicioni nostre / subiugavimus, recepimus literas dilecti militis nostri Petri Marthini de Arthesona continentes quod, ipso existente vobiscum apud Burdegale, / fuit vobis significatum quod duo archiepiscopi legati Romane Ecclesie erant Tolose venientes ad vestram presenciam pro tractatu composicionis / inter Ecclesiam et nos faciendo, et quod secunda die dominica 
Quadragesime debebant vobiscum apud Burdegalem interesse, quarum ob rem iniuncxistis dicto / Petro Martini quod ad nos remearet celeriter ut predicta nobis significaret, et nos, pro tractatu dicte composicionis die predicta ad vestram / magnificentiam nostros sollempnes nuncios mitteremus.

Nos itaque, dictis literis receptis, Barchinone impulimus incontinenti prima die mercurii / mensis marcii, ubi dictum Petrum non invenimus, cum ipse nos alibi apellere credidisset, set confestim, non obstante absencia / eiusdem, direximus nostras literas pro illis quos ad vestre serenitatis presenciam ratione dicti tractatus distinare intendimus, qui in brevi, / duce Deo, erunt vobiscum, cum, premissis ceteris nostris negociis, ad expedicionem huius totaliter intendamus.

Vestram igitur / excellenciam affectuose requirimus et rogamus quatenus placeat nos habere excusatos rationibus predictis, quia die prefixa nostri nuncii / nequiverunt vobiscum in dicto loco Burdegalis interesse.

Data Barchinone, $\mathrm{II}^{\mathrm{e}}$ nonas marcii.

6. 1287, marzo, 20. Barcelona.

Alfonso III realiza una carta de creencia a favor de Gilaberto de Cruilles, Pedro Martínez de Artasona, Raimundo de Reus y Juan Zapata ante los reyes de Inglaterra.

- ACA, Real Cancillería, reg. 64, f. 193r.

$\mathrm{XII}^{\circ}$ kalendas aprilis anno $\mathrm{LXXX}^{\circ}$ sexto, in Barchinona, fuit facta litera credencie generalis ex parte domini regis super / facto composicionis Guilaberto de Crudilis, preposito Celsonensi; Petro Martini de Artasona, magistro Raimundo de Reus / et Iohanni Çabata apud regem Anglie.

Similis fuit facta eisdem apud reginam Anglie. Data ut supra.

7. [1287], marzo, 29. Barcelona.

Alfonso III, a petición de Eduardo I, concede un guiaje a Alicia, condesa de Blois, para que pudiera hacer con seguridad un viaje a Jerusalén.

- ACA, Real Cancillería, reg. 70, f. 84r.

Alfonsus, etcetera, universis oficialibus.

Sciatis quod nos, ad instanciam et preses (sic) illustrissimi regis Anglie, guidamus / et assecuramus nobilem dominam Aliciam, comitissam de Bloys, cum familia et rebus suis omnibus quas secum duxerit. Quequidem / domina signaculo Crucis assumpto intendit iter arripere versus partes Ierosolomitanas, quare vobis dicimus et mandamus quatenus / [ipsa domina], familie vel rebus suis quas secum duxerit, tam in eundo quam etiam redeundo, nullum impedimentum vel contrarium / faciatis nec fieri permitatis.

Quicumque autem contra huiusmodi mandatum et guidaticum nostrum in aliquo venire presum/serit iram et indignacionem nostram se noverit penitus incurrisse.

Data Barchinone, IIII $^{\circ}$ kalendas aprilis. 
8. 1287, julio, 28. Oloron-Sainte-Marie.

Eduardo I y Alfonso III acuerdan el matrimonio del monarca aragonés con la infanta Leonor, primogénita de los reyes ingleses.

- Pub. Rymer, 1789: 19.

9. 1287, julio, 28. Oloron-Sainte-Marie.

Alfonso III comunica a Eduardo I que, estando próxima a expirar la tregua que Aragón mantenía con Francia, se encontraba dispuesto a prorrogarla haciendo especial hincapié a que esto afectaba a los territorios que Jaime II de Mallorca poseía en Cataluña y en el sur de Francia.

- ACA, Real Cancillería, reg. 64, f. 197v. Primer documento del folio.

- Pub. Rymer, 1789: 20.

\section{0. [1287, julio, 28. Oloron-Sainte-Marie]}

Alfonso III comunica a Eduardo I que, estando próxima a expirar la tregua que Aragón mantenía con Francia, se encontraba dispuesto a prorrogarla.

- ACA, Real Cancillería, reg. 64, f. 197v. Segundo documento del folio.

- Pub. Rymer, 1789: 20.

11. 1287, agosto, 2. Jaca.

Alfonso III informa a Eduardo I que el conde de Urgell y otros miembros de la nobleza catalana se habían personado ante él para hacerle saber que, por encontrarse Aragón en una fase de tregua con Francia, no brindarían su apoyo al conde de Foix si Felipe IV tomaba la determinación de actuar contra él, decisión a la que también se comprometía el monarca aragonés.

- ACA, Real Cancillería, reg. 64, f. 198r.

- Pub. Rymer, 1789: 20. ${ }^{17}$

12. [1287], agosto, 21. Tarazona.

Alfonso III, a petición de la reina Leonor, exculpa a Oger de Canfranc de un homicidio del que había sido acusado por el sobrejuntero de Jaca.

- ACA, Real Cancillería, reg. 75, f. 38r.

Alfonsus, etcetera, dilecto suo Roderico de Figeroles, superiunctario et merino Iacce.

Sciatis quod, ad preces illustrissime domine regine Anglie, remisimus / homicidium quod petebatis ab Ogerio de Campfranch ratione mortis Benedicti, filii Garcie de Remon, de quo erat idem Ogerius inculpatus, quare / mandamus vobis quatenus dictum

17 Rymer lo sitúa por error el día 4 de agosto al no haber transcrito correctamente la cláusula de la data. 
homicidium non petatis a dicto Ogerio. Et si aliqua pignora inde fecistis ea sibi vel quicquid inde rece/peritis restituatis incontinenti.

Data Tirasone, $\mathrm{XII}^{\mathrm{o}}$ kalendas septembris .

Iacobus de Cabanis.

13. [1288], junio, 8. Barcelona.

Alfonso III faculta a Eduardo I para prometerle a Blanca, madre de los infantes de la Cerda, que, si ella conseguía una tregua trienal entre Aragón y Francia, dichos infantes serían automáticamente liberados.

- ACA, Real Cancillería, reg. 77, f. 3v.

Noverint universi quod nos Alfonsus, etcetera, concedimus vobis, illustrissimo principi domino Eodoardo (sic), Dei gratia regi Anglie, duci Aquitanie ac domino Ybernie, plenam / potestatem et liberam facultatem promitendi ac firmandi nomine nostro quod si domina Blancha, uxor domini Ferrandi, quondam illustris regis (tachado: Anglie) Castelle primogeniti, optinuerit / nobis et nostre curie treugam trienalem ab illustri rege Francie ultra tempore treuge concesse dati a principe Salernitano propter ipsius principis deliberationem, liberabimus et / plenarie libertati restituemus infantes Castelle, filios dicte domine Blanche, scilicet, dompnos Alfonsum et Ferrandum, promitentes vobis sub obligacione omnium bonorum nostrorum / quod id quod super predictis nomine nostro promiseritis ac firmaveritis ratum ac firmum habebimus et inviolabiliter observabimus et non contra veniemus aliqua racione. / In cuius rey testimonium presenti carte sigillum nostrum maiori duximus aponendum.

Data Barchinone, sexto idus iunii.

14. [1288], junio, 10. Barcelona.

Alfonso III indica a Eduardo I que le envía a Gilaberto de Cruilles y a Ramón de Besalú como mensajeros, rogándole que les crea en lo que tienen que contarle. ${ }^{18}$

- ACA, Real Cancillería, reg. 77, f. 3r.

Illustrissimo et magnifico principi Odoardo, Dei grati regi Anglie, Alfonsus, etcetera, salutem et sincere dilectionis effectum cum con/[ti]nuo incremento.

Cum nos mitamus ad excellenciam vestram nobilem Gilabertum de Crudilis et magistrum Raimundum de Besalduno, / [archidiaconum] Ripacurcie, super nostris negociis que audietis ab eis, rogamus vos quatenus credatis eisdem lut nobis/ de hiis

18 Este documento se envío también a dos consejeros del rey inglés llamados Oto de Granson y Jean de Vezin. También se indica que se envió uno similar al conde de Lincoln. Hay algunas pequeñas variaciones en el texto, pero no son lo suficientemente significativas en mi opinión como para incluir la transcripción de un documento prácticamente idéntico. 
que / [de] parte nostra serenitati \magestati/ (tachado: serenitati) vestre expo[n]erint. Data Barchinone, IIII $^{\circ}$ idus iunii.

15. [1288], junio, 18. Barcelona.

Alfonso III escribe a Leonor, reina de Inglaterra, para pedirle que no tenga en consideración los escritos que Sancho IV, rey de Castilla, había enviado a la monarquía inglesa quejándose de los comportamientos del aragonés.

- ACA, Real Cancillería, reg. 77, f. 3v.

Illustrissime ac magniffice domine Alionori, Dei gratia regine Anglie, domine Ybernie et ducisse Aquitanie sive matri karissime, Alfonsus, etcetera, salutem et $\mathrm{s}$ [incere] / semper dilectionis continuum incrementum.

Serenitatis vestre literas nobis missas per latorem presencium, valletum illustris regis Anglie, eo quo decuit honore recepimus, (roto) [de eius?] / continencia intellecta satis turbati fuimus in nobis de hiis que illustris rex Castelle scripsit vobis nuperrime per quendam militem suum, ex eo specialiter quia per (roto)[literas?] / ipsas perpendimus, propterea nostrum fuisse turbatum animum et anxietate depressu, credentes nos fore culpabiles super eis, et salva ipsius regis Castelle (roto) [miseracione, stetit?] / et neccesarium est quod scripta vobis per eum non sic se habent nec fuerunt taliter subsecuta, et cum vos aperte sciveritis processus et tractatus habitos inter predictum regem / Castelle et nos super firmanda pace et amicitia quam semper cum eodem habere cupivimus et desideravimus, vos sencietis ex parte nostra nullum intervenisse defectum, scilicet (?) / ex parte ipsius regis qui in ultimo tractatu, super quo intendebat habere vistam nobiscum requirebat nos quedam agere que valde dampnosa et preiudicialia esse (roto) / et nobis manifestissime videbantur.

Verum quia super premissis per literas non possemus vobisl lacius aperte beneplacita mentis nostre ac etiam excusationes nostras iustas / et sufficientes pretendere, instruximus et informavimus plenarie nobilem et dilectum Gilabertum de Crudiliis [et] magistrum Raimundo de Bisalduno, archidiaconum, speciales / nuncios nostros, quos ad illustrem regem Anglie et excellenciam vestram propter hec et alia duximus transmitendos, et per eos ad plenum in brevi, cum sint in / procinctu itineris, certificari poteritis de inocencia nostra ac etiam intencione.

Bene et diu valeat vestra prosperitas per tempora longiora.

Data Barchinone, XIIII kalendas / iulii.

16. 1288, octubre, 21. Canfranc.

Alfonso III concede un guiaje a Eduardo I para que pueda desplazarse de forma segura ante la vista que iban a celebrar ambos monarcas.

- Pub. Rymer, 1789: 27. 
17. 1288 , octubre, 26. Canfranc.

Alfonso III concede un guiaje a Eduardo I y a todo su séquito para que puedan desplazarse de forma segura ante la vista que iban a celebrar ambos monarcas.

- Pub. Rymer, 1789: 27.

18. 1288, octubre, 28. Canfranc.

Alfonso III y Eduardo I suscriben el tratado de Canfranc en el que se acuerda la liberación del príncipe de Salerno por parte de Aragón y en el que se establecen los compromisos de garantía a los que se comprometía la monarquía inglesa.

- ACA, Real Cancillería, pergaminos, Alfonso III, carp. 123, docs. 242 y 243.

- Pub. Rymer, 1789: 27-29.

19. 1288 , octubre, 28. Canfranc.

Alfonso III reconoce haber recibido de Eduardo I veintitrés mil marcos de oro y plata como compensación por la liberación del príncipe de Salerno.

- ACA, Real Cancillería, pergaminos, Alfonso III, carp. 123, doc. 245.

- Pub. Rymer, 1789: 31.

20. 1288, octubre, 28. Canfranc.

Alfonso III y Eduardo I suscriben el tratado de Canfranc en el que se acuerda la liberación del príncipe de Salerno por parte de Aragón y en el que se establecen los compromisos de garantía a los que se comprometía la monarquía aragonesa.

- ACA, Real Cancillería, pergaminos, Alfonso III, carp. 123, doc. 244.

- Pub. Rymer, 1789: 32.

21. [1289, enero, 3. Valencia].

Alfonso III pide a Eduardo I que le envíe a alguien para que reciba y proteja a su mensajero Ramón de Riera que acudía ante los reyes ingleses para informarle de las gestiones que Aragón estaba realizando con la Santa Sede, rogando que la reina Leonor también estuviera presente. ${ }^{19}$

- ACA, Real Cancillería, reg. 77, f. 13r.

Fuit super predicto negocio scriptum regi Anglie ut traddet aliquem socium predicto Raymundo de Ria/ria, cum quo posset ire secure ad regem.

Item, regine Anglie quod procuret stare cum domino rege Anglie.

19 El asunto al que hace referencia al principio corresponde con el largo documento copiado anteriormente en el registro (fols. 12r.-v.) y que consiste en una carta enviada a varios cardenales a los que Alfonso III indica que el papa le había concedido seis meses para que fuera a entrevistarse con él y que no lo había podido hacer por encontrarse enfermo, suplicándoles que intercedieran por él para que le concediera una nueva cita. 


\section{1289 , marzo, 9. Peña Negra. ${ }^{20}$}

Alfonso III confirma a Eduardo I que ha recibido los veinte rehenes marselleses estipulados como una de las condiciones para la liberación del príncipe de Salerno.

- ACA, Real Cancillería, reg. 77, f. 21r. Primer documento copiado en el folio.

- Pub. Rymer, 1789: 44.

23. 1289, marzo, 9. Peña Negra.

Alfonso III reconoce el cumplimiento de las condiciones estipuladas en el tratado de Canfranc, entre las cuales se incluían treinta y seis nobles y cuarenta burgueses entregados por Eduardo I como rehenes.

- ACA, Real Cancillería, reg. 77, f. 21r.-v. Segundo documento copiado en el folio.

- Pub. Rymer, 1789: 44-45.

24. 1289, mayo, 15. Terrer.

Alfonso III pide a Eduardo I que actúe como intermediario en nombre suyo para prorrogar la tregua que Aragón había suscrito con Francia y con la Santa Sede tras la liberación del príncipe de Salerno, al no tener el rey aragonés la seguridad de que su enviado, el prepósito de Solsona, pudiera llegar hasta Roma sin peligro.

- ACA, Real Cancillería, reg. 77, f. 23r.

- Pub. Rymer, 1789: 47.

25. 1289, noviembre, 24. Lleida.

Alfonso III se queja a Eduardo I de que, tras haber liberado Aragón al príncipe de Salerno, éste no estaba cumpliendo las condiciones que se habían estipulado para ello ni la Santa Sede había levantado la excomunión que existía sobre la monarquía aragonesa.

- ACA, Real Cancillería, reg. 77, f. 27r.-28v.

- Pub. Rymer, 1789: 58-59.

26. [1289], noviembre, 30. Bellpuig.

Alfonso III escribe a la reina Leonor para que induzca a su marido Eduardo I a que cumpla la promesa que formuló a los aragoneses para que se produjera la liberación del príncipe de Salerno.

- ACA, Real Cancillería, reg. 77, f. 28v.

Fuit scriptum regine Anglie quod inducat regem Anglie, virum suum, quod compleatur domino regi / promissa per ipsum et principem Salernitanum super liberatione eiusdem.

Data in Bellopodio, $\mathrm{II}^{\mathrm{e}}$ kalendas / decembris.

Se encuentra en las proximidades del puerto de Somport (Huesca). 
27. 1290, enero, 1. Tarragona.

Alfonso III vuelve a quejarse a Eduardo I del constante incumplimiento de acuerdos por parte del príncipe de Salerno y de la negativa de la Santa Sede a la normalización de relaciones con Aragón.

- ACA, Real Cancillería, reg. 77, f. 27r.-28v.

- Pub. Rymer, 1789: 59-6121.

28. [1290, enero, 4] $]^{22}$ Tarragona.

Alfonso III comunica a Eduardo I que atiende favorablemente su petición de que el monarca aragonés concediera guiaje y protección a los partidarios del rey de Francia y de su tío Jaime II de Mallorca que se desplazaban para acordar la reparación de los daños que habían causado en periodo de tregua.

- ACA, Real Cancillería, reg. 73, f. 71v.

- Pub. Rymer, 1789: 5923.

\section{1290, enero, 18. Alcolea de Cinca.}

Alfonso III, tras haber recibido una petición de Eduardo I para que enviara procuradores a Perpignan a fin de concertar una nueva tregua entre Aragón y Francia, designa a dos peritos y a un notario.

- Pub. Rymer, 1789: 61-62.

30. [1291], mayo, 3. Barcelona.

Alfonso III escribe a Eduardo I y a la reina madre Leonor de Provenza pidiéndoles que crean a Berenguer de Pulcroviso, Juan Zapata y Guillermo Dufort.

- ACA, Real Cancillería, reg. 73, f. 103v.

Fuit missa littera illustri domino Edduardo, regi Anglie, quod credat Berengario de Pulcrovisu, sacriste / Vicensi, Iohani Çappate et Guillelmo Durforti.

Data Barchinone, $\mathrm{V}^{\circ}$ nonas madii.

(...)

Item, domine Alionore, regine maiori Anglie.

21 Rymer lo data erróneamente el 4 de enero al no haber transcrito correctamente la cláusula de la data.

22 Pese al error que tiene la cláusula de la data, se deduce el mes comparando con los documentos anterior y posterior que se encuentran copiados en el registro.

23 Rymer lo data erróneamente el 2 de enero. 


\section{Referencias bibliográficas}

BURT, Caroline (2013), Edward I and the governance of England, 1272-1307. Cambridge, Cambridge University Press.

CANELLAS LÓPEZ, Ángel (1986), «Relaciones políticas, militares y dinásticas entre la Corona de Aragón, Montpellier y los países de Languedoc de 1204 a 1349», Revista de historia Jerónimo Zurita, 53-54: 7-36.

ChAPlais, Pierre (2003), English diplomatic practice in the Middle Ages. Londres y Nueva York, Hambledon y Londres.

Cingolani, Stefano M. ${ }^{a}$ (2012), Gestes dels comtes de Barcelona i reis d'Aragól Gesta comitum Barchinone et regum Aragonie. Santa Coloma de Queralt, Obrador Edendum-URV.

Cingolani, Stefano M. (2015), Diplomatari de Pere el Gran. 2. Relacions internacionals i política exterior. Barcelona, Fundació Noguera.

COCKERILL, Sarah (2014), Eleanor of Castile. The shadow queen. Stroud, Amberley Publishing.

DARWIN SWIFT, Francis (1890), «Marriage alliance of the infanta Pedro of Aragon and Edward I of England, 9 oct. 1273», The English Historical Review, 18: 326$328 .^{24}$

DonAdo VARA, Julián, Ana EchEVARría ARsuaga y Carlos BARQuERo GoÑI (2014), Historia medieval II (siglos XIII-XV). Madrid, Editorial Universitaria "Ramón Areces".

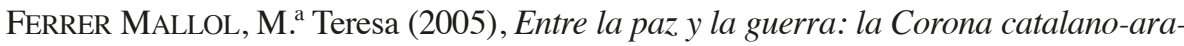
gonesa y Castilla en la Baja Edad Media. Barcelona, Institución "Milá y Fontanals". GONZÁLEZ ANTÓN, Luis (1975), Las Uniones aragonesas y las cortes del reino (12831301). Zaragoza, Escuela de Estudios Medievales.

Goodman, Anthony (1989), «England and Iberia in the Middle Ages.», En M. Jones y M. Vale (eds.), England and her neighbours, 1066-1453. Essays in honour of Pierre Chaplais. Londres y Ronceverte, The Hambledon Press: 73-96.

JoRDÁn DE URRíES y José AZARA (1914), «La política exterior de Alfonso III de Aragón», Boletín de la Real Academia de Buenas Letras, VII: 411-458 y 472-485.

KLÜPFEL, Ludwig (1911), Die äussere politik Alfonsos III von Aragonien (1285-1291) mit einem anhang. Beiträge zur geschichte der inneren politik Alfonsos. Basilea, Verlag für Recht und Gesellschaft.

LA MANTIA, Giuseppe (1908), «Documenti su le relazioni del re Alfonso III di Aragona con la Sicilia (1285-1291)», Anuari de l'Institut d'Estudis Catalans, 11: 337-363.

MARZAL GARCíA-QuiSMONDO, Miguel (1997), «La perspectiva catalano-aragonesa de D. Jaime de Sicilia», Revista de historia medieval. Anales de la Universidad de Alicante, 11: 417-444.

24 El error en el título se encuentra en el original. 
MASIÀ DE Ros, Àngels (1992), «Las pretensiones de los infantes de la Cerda a la Corona de Castilla en tiempos de Sancho IV y Fernando IV», Medievalia, 10: 255-279.

PARPAl I MARQUÉS, Cosme (1964), La conquesta de Menorca, el 1287, per Alfons el Liberal. Barcelona, Rafael Dalmau.

PlAIDY, Jean (1996), Eduardo Piernaslargas. Barcelona, Plaza \& Janés.

PRESTWICH, Michael (2008), Edward I. New Haven y Londres, Yale University Press.

RÁBADE OBRAdó, María del Pilar, Eloísa RAmíREZ VAQUERO y Juan Fernando UTRILLA UTRILlA (2005), La dinámica política. Madrid, Istmo.

REEDY, Gerard (1978), «Rymer and History», Clío, 7.3: 409-422.

RiVERO GONZÁleZ, Isabel (1982), Compendio de historia medieval española. Madrid, Istmo.

RYMER, Thomas (1789), Foedera, conventiones, literae et cuiuscumque generis acta publica inter reges Angliae et alios quosvis imperatores, reges, pontifices, principes vel comunitates. La Haya, Jean Neaulme. Disponible en red.

SÁNCHEZ MARTíNEZ, Manuel (1998), «1289/92 y 1342/44: dos fechas cruciales en la evolución de la fiscalidad real y urbana en Cataluña.» En Pau Cateura Bennàsser, coord., El regne de Mallorca a l'època de la dinastia privativa. XVI jornades d'Estudis Històrics Locals. Palma del 10 al 12 de desembre de 1997. Palma de Mallorca, Institut d'Estudis Baleàrics.

SARASA SÁnCHEZ, Esteban (1984), El Privilegio General de Aragón. La defensa de las libertades aragonesas en la Edad Media. Zaragoza, Gobierno de Aragón.

SoldeVila i Zubiburu, Ferrán (1963), Vida de Pere el Gran i d'Alfons el Liberal. Barcelona, Aedos.

TouT, Thomas Frederick (1905), The History of England from the accession of Henry III to the death of Edward III (1216-1377). Longmans, Green and Company.

WALKER, Rose (2007), «Leanor of England and Eleanor of Castile: Anglo-Iberian marriage and cultural exchange in the twelfth and thirteenth centuries.» En M. Bullón-Fernández, ed., England and Iberia in the Middle Ages, 12th-15th century. Cultural, literary and political exchanges. Nueva York, Palgrave Macmillan. 
